\title{
Biologists join drive to turn down the lights
}

Steve Nadis, Boston

The fight against light pollution is becoming a multidisciplinary endeavour. Last week's meeting of the International Dark-Sky Association (IDA), which would once have been an event purely for astronomers, featured researchers working on topics as diverse as migratory birds and breast cancer.

Astronomers attracted little interest when they first complained about the glow from urban areas in the 1950s, but the dark-sky movement has grown rapidly since the IDA was formed in 1988. Astronomy was deliberately played down at this year's meeting, and was the subject of only one of some 40 presentations. "If it's just a concern for astronomers, many people will dismiss this as a narrow, special-interest group," says Dan Green of the Harvard-Smithsonian Center for Astrophysics in Cambridge, Massachusetts, one of the event's organizers. "We're stressing the security, energy-efficiency, health and ecological benefits of good lighting."

Cancer epidemiologist Richard Stevens, from the University of Connecticut in Farmington, provided one example of this wider focus. He discussed potential links between the increased incidence of breast cancer, especially in the industrialized world, and the way in which exposure to light at night can disrupt natural secretion cycles of the hormone melatonin. Low levels of melatonin, which is thought to be responsible for our daily, or circadian, biological rhythms, have been linked to breast cancer.

Stevens cited recent studies of visually impaired men and women, which show that breast-cancer risk declines with decreasing vision (P. K. Verkasalo et al. Br. J. Cancer 80, 1459-1460; 1999). Although Stevens' work is not specifically concerned with light pollution, other meeting participants tried to make the link, suggesting that 'light trespass' into homes and apartment buildings from street lights and other sources is more than capable of perturbing circadian rhythms.

Other speakers addressed risks posed to migrating birds by outdoor artificial lighting. Ornithologist Richard Podolsky of the Technology Planning and Management Corporation, an environmental services organization based in Scituate, Massachusetts, described his research of offshore birds. Atlantic puffins, which rely on the Moon for navigation, become confused by illuminated structures at sea, says Podolsky, often circling them until they crash or die of exhaustion.

Delegates at the meeting also paid tribute to the progress made by the IDA. David Crawford, an astronomer from Kitt Peak National Observatory in Tucson, Arizona, and the IDA's executive director and cofounder, began the campaign in the late 1960 s by joining the Illuminating Engineer-

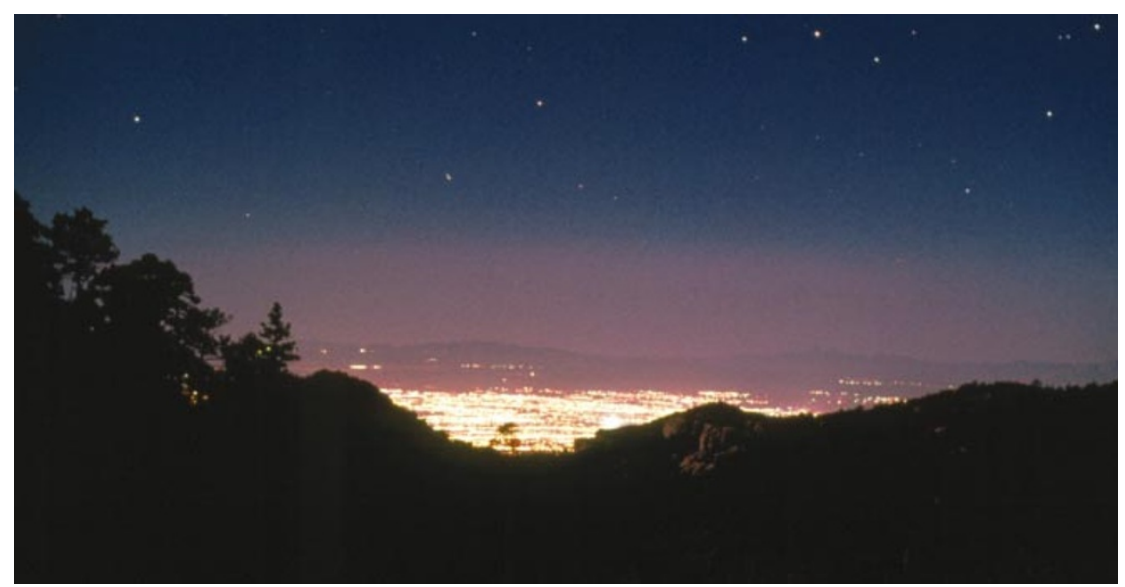

Ray ban: astronomers have long campaigned for limits to the amount of light pollution from cities.

ing Society of North America (IESNA), an organization that aims to set standards for outdoor lighting. "Two decades ago, we hated those guys and used to run from them," recalls IESNA president Randy Reid. "We thought they were a bunch of left-wing lunatics. But Crawford persuaded us that he didn't want to turn the lights out, he just wanted us to direct light where it was needed, without illuminating the whole sky."

\section{Japan plans web of English journals}

David Cyranoski, Tokyo

Japan is aiming to increase its already significant presence in international research by launching a set of electronic English-language journals.

Last month the education ministry requested $¥ 180$ million (US\$1.4 million) from the government, which is expected to be granted by the end of the year, to launch the plan.

The National Institute of Informatics (NII) in Tokyo will provide the technology required for the journals. The institute will also select the fields in which the first four or five journals will be launched. The relevant Japanese academic societies will recommend editorial-board members. Each journal will ask referees from across the world to review its papers, and will be expected to be selfsupporting after three years.

The NII will collaborate with the Scholarly Publishing and Academic Resources Coalition (SPARC), an initiative established by libraries in the United States and Europe to reduce journal costs by distributing online publications at affordable prices (see Nature 398, 272; 1999). SPARC will also help the NII to develop a business model for the journals, and will help it to find buyers for the new online journals, say planners at the education ministry.

If the new online journals provide high impact and value for money, libraries will favour them over more expensive ones, says an official from one national university library. But the plan is not just about cost-cutting. "The project came about also because the education ministry is keen to enhance the reputation of Japan's research," says Syun Tutiya, a philosopher and former librarian at Chiba University, north of Tokyo, who hopes to set up an equivalent to SPARC in Japan.

Ministry officials are playing down the implication that European and US journals neglect Japanese research, but say that researchers are frustrated at having to submit to US and European journals. "Many researchers prefer to submit their papers to a Japanese journal, and will continue to do so, because they're concerned they won't get fair treatment elsewhere," says Mikiko Tanifuji of the Institute of Pure and Applied Physics in Tokyo, which publishes four journals, including the Japanese Journal of Applied Physics.

Japanese scientists say that a successful journal could be a boon for research if it is able to bring in submissions and peer reviewers from around the world. But they worry that the nominally international effort could become a nationalistic enterprise that merely advertises Japanese research.

The key to the journals' success will be finding fields in which Japan excels, researchers say. "The question is whether the journals will actually be used," says Tanifuji.

www.nii.ac.jp 